\title{
PEMBERDAYAAN PRODUKSI TAHU BAKSO DAN KETAN LUPIS, DI KELURAHAN PRENGGAN KOTA GEDE, YOGYAKARTA
}

\author{
Juhari'1), Ulung Pribadi1), Rossi Maunofa Widayat ${ }^{2)}$ \\ 1)Program Studi Ilmu Pemerintahan, Fakultas IImu Sosial dan Politik, Universitas Muhammadiyah Yogyakarta, \\ Yogyakarta, NTB, Indonesia \\ 2)Program Studi IImu Pemerintahan, Fakultas IImu Sosial dan Politik, Universitas Muhhamdiyah Mataram, Mataram, \\ NTB, Indonesia \\ Corresponding author: Rossi Maunofa Widayat \\ E-mail : widayatrossi@gmail.com
}

Diterima 30 Juli 2021, Direvisi 01 Agustus 2021, Disetujui 02 Agustus 2021

\begin{abstract}
ABSTRAK
Pendapatan pengusaha UMKM (Usaha Mikro Kecil Menengah) tahu bakso "Enak" dan UMKM ketan lupis mengalami penurunan pendapatan sejak pandemi covid-19. Selain itu kendala lain yang dihadapi yaitu belum adanya pemanfaatan media sosial dalam strategi pemasaran di tengah dunia digitalisasi, packaging produk yang masih sederhana sehingga kurang menarik konsumen, dan tidak adanya manajemen keuangan yang baik disaat banyaknya pendapatan dan pengeluaran produk. Dari permasalahan mitra tersebut UMY melalui program pengabdian kepada masyarakat yang disinergikan melalui Kuliah Kerja Nyata (KKN) memiliki beberapa program kegiatan untuk mengatasi permaslahan mitra. Program ini ditujukan untuk meningkatkan kualitas penjualan serta pemasaran tahu bakso "Enak" dan ketan lupis di tengah pandemi covid-19. Kedua UMKM telah diberikan sosialisasi serta pelatihan menggunakan media sosial di era digitalisasi dan untuk membantu pemilik UMKM dalam mengatasi penurunan penjualan di masa pandemi Covid-19. Tim pengabdi telah membuatkan akun media sosial, dan juga telah membuatkan logo dan pamflet yang nantinya akan disebarkan melalui media sosial agar dapat meningkatkan hasil penjualan. Serta menciptakan packaging product yang menarik sehingga menambahkan daya tarik konsumen.
\end{abstract}

Kata kunci: UMKM ; manajemen keuangan ; media sosial ; manajemen pemasaran

\begin{abstract}
Entrepreneurs of "tahu bakso" and "ketan lupis " as Micro, Small and Medium Enterprises ("UMKM") face obstacles, especially in the era of the covid-19 pandemic. First, they package the product in a simple way so that it does not attract the attention of consumers. Second, they have not used social media as a marketing strategy in the current digital age. Third, they do not have good financial management. As a result, their income is small and even tends to decline. The UMY Community Service Team together with KKN students have implemented programs and activities to help these small entrepreneurs. The team has trained the entrepreneur on how to package the product in an innovative way. This team has also socialized the use of social media to market products creatively. Lastly, this team has helped with how to manage finances properly. This team wants to achieve the goal, which is that small entrepreneurs can expand their marketing and increase the number of buyers, so that their income increases significantly
\end{abstract}

Keywords: UMKM; financial management ; social media ; marketing management

\section{PENDAHULUAN}

Pembangunan dan perkembangan perekonomian negara - negara berkembang seperti di Indonesia sangat bergantung pada "Usaha mikro kecil dan menengah" (UMKM). Hal ini dikarenakan "usaha mikro kecil dan mengengah" banyak menyerap tenaga kerja sehingga berdampak pada berkurangnya jumlah pengangguran dan dapat meningkatkan pendapatan per kapita suatu negara. Sektor usaha mikro, kecil dan menengah (UMKM) juga memiliki kontribusi dalam hal meningkatkan jumlah produk domestic bruto (Pakpahan, 2020).

"Usaha Mikro Kecil Menengah" atau disingkat UMKM memiliki peran penting dalam pertumbuhan ekonomi di Indonesia. Peran tersebut diantaranya adalah mampu menyerap tenaga kerja, mengatasi masalah kemiskinan dan membantu pendistribusian hasil-hasil pembangunan (Hapsoro et al., 
2019) . Di Indonesia, sektor bisnis seperti fashion,kuliner dan kerajinan menjadi yang paling diminati. Sedangkan UMKM dalam bidang jasa tidak banyak diminati dikarenakan tantangan untuk berinovasi memberikan pelayanan yang cepat dan efisien yang didukung dengan penggunaan teknologi (Koeswandi \& Primaskara, 2020). Perannya yang penting sebagai 'tulang punggung' perekonomian Indonesia tidak ditunjukan dengan pertumbuhan yang signifikan setiap tahun. Pertumbuhan UMKM di Indonesia terus menurun terutama dalam industri jasa (Laura, 2020).

$$
\text { Penyebabnya kegagalan }
$$

berkembangnya UMKM terletak pada fungsi saluran pemasaran yang tidak optimal. Saluran pemasaran yang baik mencakup segala upaya pemenuhan kebutuhan produk/jasa mulai dari produsen, supplier, distributor hingga konsumen dengan menciptakan \& menawarkan nilai. Dari hulu ke hilir, saluran distribusi yang efektif dibangun dengan trust dan komitmen agar target perusahaan dapat tercapai (Sugiri, 2020).

Pandemi covid-19 yang melanda Indonesia sangat mempengaruhi beberapa sektor terutama pada sektor perekonomian, yang dalam hal ini para pengusaha UMKM karena menurunnya omset pendapatan. Mulai menurunnya omset pendapatan para pelaku UMKM ini salah satunya dikarenakan adanya kebijakan pemerintah untuk memutus mata rantai wabah covid-19 dengan PSBB (Pembatasan Sosial Bersakala Besar) di berbagai wilayah. Tujuan dari diberlakukannya kebijakan tersebut untuk menjaga keselamatan para warganya dimasa pandemi ini sehingga menurunnya daya beli konsumen pada usaha bisnis para UMKM tersebut (Alfrian \& Pitaloka, 2020).

Kelurahan Prenggan merupakan salah satu kelurahan dari tiga kelurahan yang ada di Kecamatan Kota Gede yaitu Keluruhan Rejowinangun, Kelurahan Pandeyan, Keluruhan Purbayan. Kelurahan Prenggan mempunyai slogan "Prenggan Bergelora" (Bergerak, Gotong Royong, Peduli, Inovaif, dan ramah untuk semua). Kelurahan Prenggan terdiri dari $13 \mathrm{RW}$ dan $57 \mathrm{RT}$, yang dibagi menjadi tiga Kampung yaitu Kampung Tinalan : RW 01-04 dan RW 12, Kampung Prenggan RW 05-10 dan RW 13, Kampung Tegalgendu RW 11.
Persoalan di dua UMKM yaitu pertama, UMKM Tahu Bakso milik Ibu Susi Ananingtyas yang diberi nama Tahu Bakso "Enak",tahu Bakso "Enak" mulai bediri sejak tahun 2010 didirikan oleh Ibu Susi Ananingsih, sampai saat ini usaha tersebut telah mempunyai dua tenaga kerja. Tahu bakso "Enak" hanya melayani pesanan dan dititipkan di warung-warung sekitar. Awalnya tahu bakso milik Ibu Susi pernah mengalami puncak dari larisnya penjualan tahu bakso yaitu dengan penjualan 400-500 biji per hari dengan harga Rp 2000,setiap biji. Akan tetapi dengan banyaknya kendala dan kondisi pandemi Covid-19 saat ini memaksa usaha tahu bakso "Enak" menjadi turun omset penjualan menjadi 100-400 biji per hari.

Persoalan kedua, UMKM Ketan Lupis Resep Mbah Waji Tempo Dulu milik Ibu Suarti. UMKM "Ketan Lupis Resep Mbah Waji Tempo Dulu"yang telah berdiri sejak lama dan sampai saat ini sudah dijalankan oleh generasi kedua yaitu Ibu Suarti. Usaha milik Ibu Suarti menjual berbagai makanan khas Yogyakarta yaitu ketan lupis dan gethuk thiwul. Penjualan dari generasi pertama berada di lapangan Karang, akan tetapi adanya kendala usia pemilik maka usaha ketan lupis sempat terhenti. Berhentinya usaha ketan lupis tidak berlangsung lama karena usaha ini di teruskan oleh generasi kedua yaitu lbu Suarti dan dibantu oleh dua tenaga terja. Produksi "Ketan Lupis Resep Mbah Waji Tempo Dulu" dilakukan di tengah malam dan dijual dari pukul 06.00 sampai 09.00 WIB di lapangan Karang. Usaha "Ketan Lupis Resep Mbah Waji Tempo Dulu" sudah berjalan dengan baik karena mampu bertahan sampai dua generasi akan tetapi terdapat beberapa kendala yang dihadapi oleh usaha ketan lupis milik Ibu Suarti ini.

\section{METODE}

Oleh karena itu melalui program KKN PPM dan juga dibantu oleh sejumlah mahasiswa yang saat ini sedang melaksanakan KKN di Kelurahan Prenggan dapat membantu tim pengabdian untuk memberikan sosialisasi, pelatihan serta pendampingan kepada kedua UMKM agar dapat mengoptimalkan pemasaran produk sehingga tetap bertahan dan berproduksi di masa pandemi covid-19 dengan menggunakan mengubah kemasan dan metode pemasarannya menggunakan media sosial. Kegiatan ini dilaksanakan selama bulan Januari-Juli 2021, bentuk dari kegiatan ini nantinya akan lebih pada berupa sosialisasi, pelatihan, serta pendampingan dengan kedua UMKM yakni pertama, "Mitra Rumah Produksi Tahu Bakso Ibu Suci" dan mitra kedua, "Ketan Lupis Resep Mbah Waji Tempo Dulu”. Untuk itu 
solusi yang ditawarkan pertama, sosialisasi memperkenalkan media sosial kepada kedua UMKM mengenai fungsi media sosial terutama sebagai alat yang digunakan untuk memasarkan produk-produk yang akan dijual ke konsumen. Kedua, pelatihan dalam hal ini nantinya tim pengabdi akan mengadakan pelatihan selain mengoperasionalkan media sosial kepada kedua UMKM dengan mengundang Tim dosen dan mahsiswa UMY sebagai nara sumber pada kegiatan tersebut, juga memberikan pelatihan bagaimana cara mengatur manajemen keuangan hasil penjualan. Ketiga, pendampingan dalam hal ini tim pengabdian yang dibantu dengan sejumlah mahasiswa dan tim dosen memberikan pendampingan bagaimana packaging product dan upload di media sosial, serta produk yang nantinya akan dipasarkan.

Sebelum melakukan pengabdian tim bersama anggota mahasiswa $\mathrm{KKN}$ yang berjumlah 10 orang yang ikut mempersiapkan pelaksanaan kegiatan KKN-PPM dengan kegiatan meliputi (1) Penyusunan jadwal agenda, persiapan ini dilakukan untuk menyusun jadwal-jadwal kegiatan bersama anggota KKN, agar jadwal agenda yang sudah dipersiapkan sesuai dengan jadwal program kegiatan yang sudah disusun oleh anggota KKN. Sehingga kegiatan KKN-PPM juga masuk dalam kegiatan program pada mahasiswa KKN selama proses kegiatan KKN. (2) Modul materi pelatihan, persiapan ini dilakukan oleh tim pengabdian masyarakat dengan nantinya sesuai jadwal yang telah ditentukan akan mengundang nara sumber-nara sumber terkait program kegiatan yang akan disampaikan dalam bentuk sosialisasi, pelatihan yang pesertanya dari kedua UMKM yakni pertama, "Mitra Rumah Produksi Tahu Bakso Ibu Suci" dan mitra kedua, "Ketan Lupis Resep Mbah Waji Tempo Dulu". Nantinya para peserta akan dibagikan modul/ materi dari setiap kegiatan yang diikuti. (3) Persiapan sarana dan prasarana, persiapan ini dilakukan antara tim pengabdi masyarakat dengan anggota KKN yang berjumlah sepuluh oang untuk berkoordinasi dengan kedua mitra terkait ketersediaan sarana dan prasarana selama proses kegiatan. (4) Koordinasi lapangan, persiapan ini dilakukan dengan melibatkan anggota KKN yang nantinya memiliki peran dalam setiap kegiatan sehingga diharapkan semua proses kegiatan berjalan dengan lancar, dan setiap kegiatan anggota KKN dibagi menjadi dua tim yang memiliki tugas dan tanggungjawab yang berbeda-beda di setiap kegiatan yang dilaksanakan. (5) Sosialisasi dengan mengumpulkan stakeholders, persiapan ini dilakukan tim pengabdian dengan mengundang seluruh anggota kedua UMKM, Ketua RW dan RT Kelurahan Prenggan, tokoh masyarakat, dan tokoh pemuda. Maksud serta tujuan pemberitahuan terkait kegiatan pengabdian ini serta menerima masukan dari berbagai pihak mengenai program-program yang akan dilaksanakan.

\section{HASIL DAN PEMBAHASAN}

Kelurahan Prenggan merupakan salah satu wilayah Kotagede yang mempunyai keanekaragaman budaya dan kuliner, sehingga potensi wisata dan ekonomi masyarakat sangat besar seperti masjid perak, kerajinan perak, lorong ndarakan, kuliner Kipo dan lain sebagainya. Banyaknya situs sejarah, arsitektur tradisional, makanan tradisional, kesenian tradisional, dan produk kerajinan inilah yang menjadi peluang besar masyarakat Prenggan, Kotagede untuk memanfaatkan potensi sebagai wisata dan kuliner.

Berbagai peluang di wilayah Prenggan, Kotagede inilah yang dimanfaatkan oleh UMKM Tahu Bakso "Enak" milik ibu Susi Ananingsih dan UMKM "Ketan Lupis Resep Mbah Waji Tempo Dulu" milik ibu Suwarti untuk memanfaatkan potensi ekonomi. Dengan memanfaatkan potensi wisata yang ada, produk Tahu Bakso "Enak" ini dijual dengan cara dititipkan ke sentra-sentra kuliner wisata Kotagede. Berbeda dengan produk Tahu Bakso "Enak", produk "Ketan Lupis Resep Mbah Waji Tempo Dulu" dijual dengan secara langsung di Lapangan Karang, Prenggan, dimana lapangan tersebut adalah tempat berkumpulnya kuliner di Prenggan sehingga potensi pembeli wisatawan sangat besar.

Setelah tim pengabdian melakukan kunjungan untuk melakukan observasi pada tanggal 15 Januari 2021 ke UMKM Tahu Bakso "Enak"dan UMKM ketan lupis, pemilik memberikan usulan terkait program yang nantinya akan tim pengabdi lakukan. Pertama agar dibantu dalam proses pemasaran. Kedua dalam proses kemasan. Pada tanggal 31 Januari tim pengabdi mengadakan kegiatan sosialisasi dan pembuatan logo serta pamflet foto produk UMKM Tahu Bakso "Enak"dan UMKM Ketan Lupis "Resep Mbah Waji Tempo Dulu" hasil dari kegiatan ini mitra dapat memahami pentingnya logo dan pamflet sebagai branding product yang nantinya bisa digunakan untuk pemasaran menggunakan media sosial. 


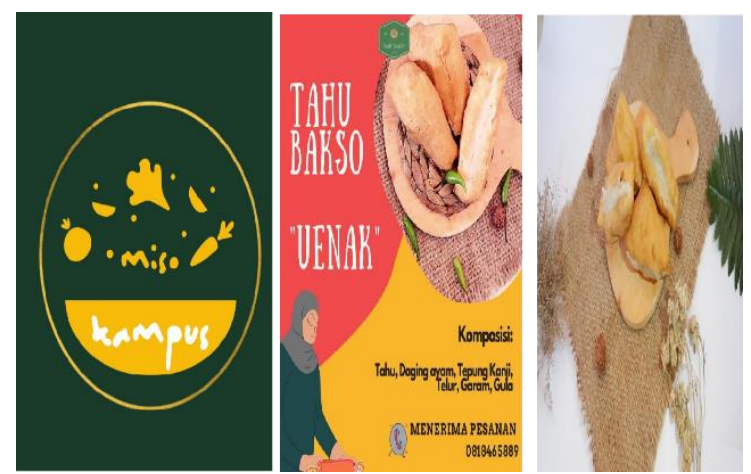

Gambar 1: Pembuatan logo dan pamflet, dan foto produk UMKM Tahu Bakso "Enak"

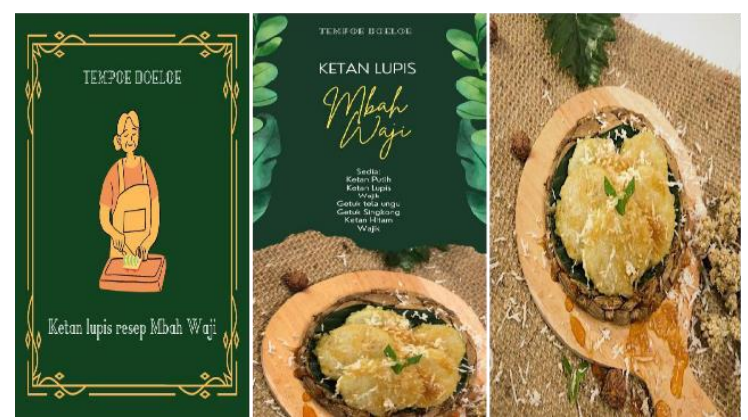

Gambar 2 : Pembuatan logo dan pamflet,dan foto produk UMKM Ketan Lupis "Resep Mbah Waji Tempo Dulu"

Branding merupakan cerminan merek suatu perusahaan, dan logo adalah bagian penting dari pengakuan merek. Peran logo sangat penting untuk mendukung kemajuan suatu bisnis, dan menjadi salah satu tanda pengenal yang efektif sehingga mudah diidentifikasi dan diingat oleh orang banyak. Ciri khas produk menjadi hal penting untuk dilakukan karena untuk membedakan dengan produk sejenis yang lain. Logo bisa diibaratkan sebagai suatu pengakuan dari sebuah merek usaha. Logo berkualitas mampu menarik minat masyarakat untuk lebih cepat dalam mengakui sebuah jasa atau produk dari bisnis yang dijalankan.

Hal ini juga memberikan manfaat tambahan, sebagai merek perusahaan logo dapat membantu meningkatkan penjualan produk baru perusahaan karena pelanggan dapat mengasosiasikan kualitas produk yang telah dikenal masyarakat luas dengan kualitas produk baru menggunakan logo yang sama. Suatu logo mampu mempengaruhi konsumen agar lebih tertarik membeli produk yang dipasarkan. Selain itu, masyarakat juga akan lebih mudah mengingat produk. Secara tidak langsung bahwa branding mampu memberikan banyak manfaat, termasuk dalam memengaruhi calon konsumen, brand yang ditawarkan ke konsumen dengan perlahan akan memengaruhi mereka untuk membeli produk.
Setelah ke dua UMKM memlikiki logo serta pamflet produk, tim pengabdi juga melakukan kegiatan sosialisasi dan pelatihan packaging product pada tanggal 18 Februari. Kedua mitra sangat antusias dalam mengikuti sosialisai packaging product yang diikuti oleh semua anggota / karyawan dari kedua UMKM. Dengan adanya kegiatan packaging product saat ini kedua UMKM telah memiliki kemasan produk yang jauh lebih bagus dari sebelumnya serta telah memiliki logo.

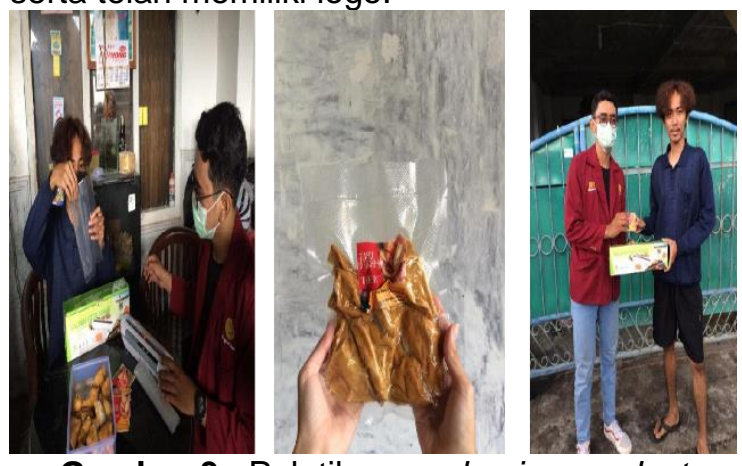

Gambar 3 : Pelatihan packaging product kedua mitra UMKM

Kemasan menjadi salah satu unsur yang sangat penting bagi suatu produk. Fungsi utama suatu kemasan adalah sebagai identitas produk, melindungi produk, menjadi daya tarik bagi konsumen, menyajikan informasi yang dibutuhkan seputar produk. Lebih dari sekedar pembungkus, kemasan merupakan branding. Apapun jenis barang atau produk yang akan dijual ketika diberi merek dan dikemas akan memberikan nilai lebih. kemasan itu dibuat bagus dan memiliki personality yang kuat akan mampu meningkatkan rasa percaya dari konsumen saat memilih produk yang akan dibelinya.

Ketika sebuah pengemasan dibuat dengan bentuk unik dan warna yang menarik akan lebih mudah menarik perhatian. Dan selanjutnya, konsumen tersebut akan mengambil, lebih banyak mengamati, dan mempertimbangkan untuk membelinya. Artinya, pengemasan sebagai salah satu senjata, telah berjalan dengan baik. Banyak pengusaha makanan ringan yang hanya melakukan repackaging atau mengemas ulang saja dari produk yang dijualnya. Semisal pada pengemasan keripik. Para pengusaha pada makanan tersebut hanya mengemas keripik yang dibuat massal oleh home industry. Tentunya, dengan berbagai persyaratan standar si pengusaha agar produk tersebut memiliki nilai jual.

Dari kegiatan pelatihan packaging product tim pengabdi juga berhadap ada perubahan peningkatan dari penjualan kedua mitra karena mulai dari kemasan yang sudah 
berubah serta disertai logo produk setidaknya bisa memiliki nilai jual dan menjadi pembanding dengan produk yang lainnya. Disamping itu juga nantinya pemasarannya akan menggunakan aplikasi media sosial, yang oleh tim pengabdi akan diberikan pelatihan bagaimana cara mempromosikan produk dengan menggunakan media sosial.

Sosialisasi dan pembuatan akun media sosial ke dua UMKM mitra dilaksanakan pada tanggal 3 Maret, tujuan dibutnya akun media sosial seperti halnya instagram dan juga facebook untuk memanfaatkan peluang promosi produk di era digitalisasi dan ditengah merebaknya pandemi covid-19 yang secara langsung telah membuat kedua UMKM merubah metode pemasarannya. Pada kegiatan ini ke dua mitra sangat antusias karena dari kegiatan Tahu Bakso "Enak"dan UMKM ketan lupis mempunyai media sosial.

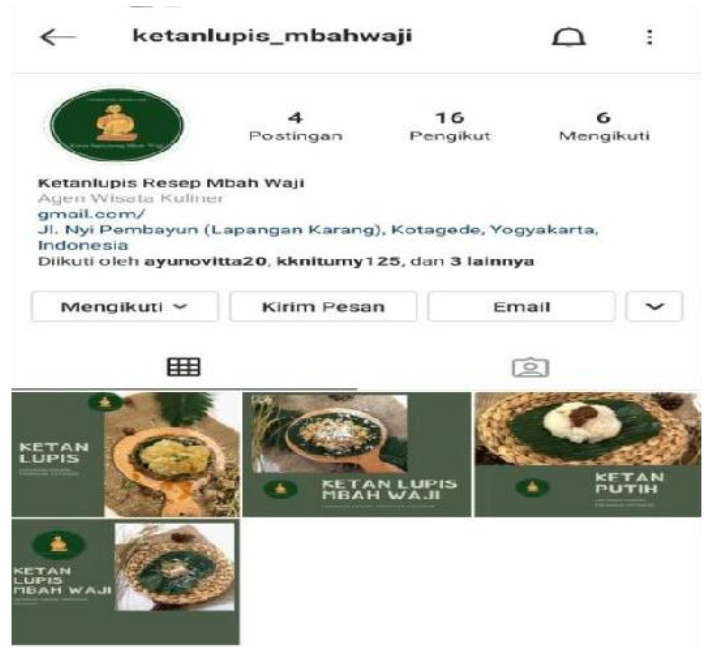

Gambar 4 : Pelatihan media sosial kedua mitra UMKM

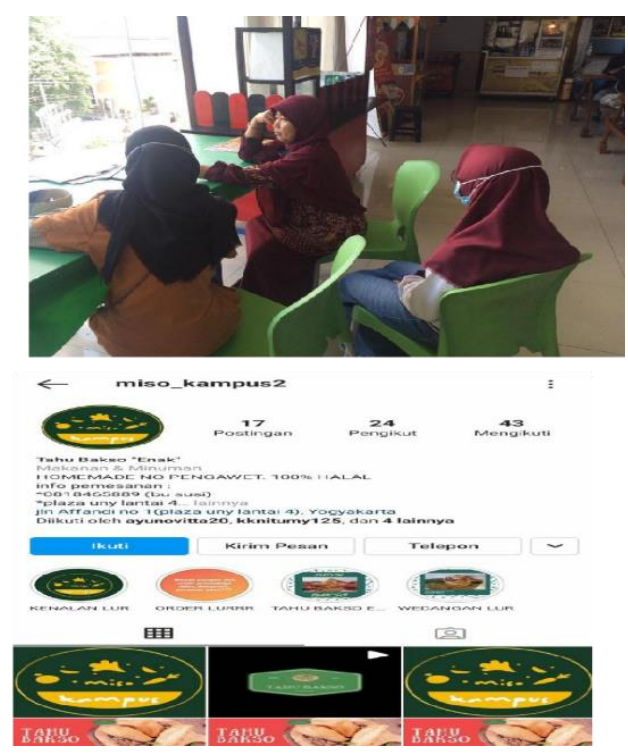

Gambar 4 : Pelatihan media sosial kedua
Volume 4, Nomor 3, Agustus 2021. p-ISSN : 2614-5251 e-ISSN : 2614-526X

mitra UMKM

\section{SIMPULAN DAN SARAN}

UMKM tahu bakso "Enak" dan UMKM ketan lupis "Resep Mbah Waji Tempo Dulu" telah memiliki media sosial yang dapat mempermudah untuk memasarkan produkproduk yang akan dijual ke konsumen. UMKM telah memiliki logo dan pamflet yang nantinya akan disebarkan melalui media sosial agar dapat meningkatkan hasil penjualan. UMKM telah menggunakan packaging product yang labih menarik sehingga menambahkan daya tarik konsumen. Kami berharap program kerja yang telah kami laksanakan di Kelurahan Prenggan dapat dilanjutkan dan membawa manfaat kepada mitra sehingga dapat mengoptimalkan pemasaran produk dan tetap berproduksi di masa pandemi covid-19.

\section{UCAPAN TERIMAKASIH}

Ucapan terimkasih disampaikan kepada Rektor Universitas Muhammadiyah Yogyakarta untuk pembiayaan pengabdian ini, melalui Lembaga Penelitian Publikasi Pemberdayaan Masyarakat (LP3M) Universitas Muhammadiyah Yogyakarta TA. 2020/2021.

Tim pengabdi juga mengucapkan terimakasih kepada kedua UMKM yakni pertama, "Mitra Rumah Produksi Tahu Bakso Ibu Suci" dan mitra kedua, "Ketan Lupis Resep Mbah Waji Tempo Dulu" yang ada di Kelurahan Prenggan, Kota Gede Yogyakarta.

\section{DAFTAR RUJUKAN}

Alfrian, G. R., \& Pitaloka, E. (2020, November). Strategi Usaha Mikro, Kecil, Dan Menengah (Umkm) Bertahan Pada Kondisi Pandemik Covid 19 Di Indonesia. In Prosiding Seminar Nasional Terapan Riset Inovatif (SENTRINOV) (Vol. 6, No. 2, pp. 139146)]

Hapsoro, B. B., Palupiningdyah, P., \& Slamet, A. (2019). Peran Digital Marketing sebagai Upaya Peningkatan Omset Penjualan Bagi Klaster UMKM di Kota Semarang. Jurnal Abdimas, 23(2), 117-120

Koeswandi, T. A., \& Primaskara, E. A. (2020). Analisis Saluran Pemasaran Terintegrasi UMKM Badii Farm Purwakarta dalam Meningkatkan Volume Penjualan. JURNAL ILMU MANAJEMEN DAN BISNIS, 11(1), 7580

Laura Hardilawati, W. (2020). Strategi Bertahan UMKM di Tengah Pandemi Covid19. jurnal akuntansi dan ekonomika, 10(1), 89-98 
Sugiri, D. (2020). Menyelamatkan usaha mikro, kecil dan menengah dari dampak pandemi Covid-19. Fokus Bisnis: Media Pengkajian Manajemen dan Akuntansi, 19(1), 76-86

Pakpahan, A. K. (2020). Covid-19 Dan Implikasi Bagi Usaha Mikro, Kecil, Dan Menengah. Jurnal IImiah Hubungan Internasional, 59-64 